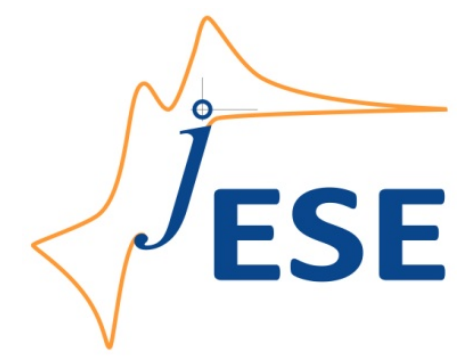

Open Access : : ISSN 1847-9286

www.jESE-online.org

Original scientific paper

\title{
Effective numbers of electrons as a criterion of carbon suitability as a hemosorbent
}

\author{
MOGELY KHUBUTIYA, BORIS GRAFOV*, MIKHAIL GOLDIN**凶, ALEXEI DAVYDOV*, \\ VLADIMIR KOLESNIKOV*** and MARK GOLDIN
}

N.V. Sklifosovsky Research Institute of Emergency Medicine, Sukharevskaya pl. 3, Moscow, 129010, Russia

${ }^{*}$ A. N. Frumkin Institute of Physical Chemistry and Electrochemistry, Russian Academy of Sciences, Leninskii pr. 31, Moscow, 119991, Russia

**Liberty University, 1971 University Blvd., Lynchburg, VA 24502-2213, USA

***D.I. Mendeleev University of Chemical Technology of Russia, Miusskaya pl. 9, Moscow, 125047, Russia

${ }^{\square}$ Corresponding Author: E-mail: mgoldin@liberty.edu; Tel.: +1-434-582-2210; Fax: +1-434-582-2488

Received: May 20, 2011; Revised: August 01, 2011; Published: August 20, 2011

\begin{abstract}
The number of medical applications of electrochemistry has grown in recent years due to the increased applications of electrochemical concepts to various systems of the organism. This includes electrochemically controlled hemosorption detoxification, where the removal of toxicants is controlled by changing the potential of the hemosorbent. It is important to avoid Faradaic processes in the course of hemosorption, which can lead to the addition of electrochemically modified toxicants to blood. The probability of their occurrence should depend on the open-circuit potential of the activated carbon. In order to elucidate the identification of Faradaic reactions, a model system was investigated. The adsorption of copper ions, tert-butanol and acetone on samples of electrochemically modified AG-3 activated carbon hemosorbent with various open-circuit potentials was used as a model of the detoxification processes. The effective number of electrons transferred in the elementary act of adsorption was shown to be a non-zero quantity for all three cases, which corroborates an electrochemical mechanism of hemosorption. For the cupric ions, ranges of open-circuit potentials were identified corresponding to different mechanisms of adsorption and Faradaic processes.
\end{abstract}

\section{Keywords}

Activated carbon; Thermally expanded graphite; Hemosorption; Open-circuit potential; Effective number of electrons 


\section{Introduction}

A continual increase of the number of applications of electrochemistry in modern medical technologies is primarily due to the broader use made of theoretical electrochemical concepts in the functioning of various systems of the human organism. Of note here are the works of Sawyer et al. [1-2] on electrochemically induced intravascular thrombosis (blood clotting) by introducing anodically polarized metal conductors into damaged blood vessels in order to attract negatively charged blood components to the electrode and stop the hemorrhage. These investigations were continued by Guglielmi, et al. and applied for the treatment of aneurisms [3-6].

At the present time, one of the leading applications of electrochemical concepts in medicine is the ideas of Nordenström and his model of homeostasis as a biologically closed electric circuit [7], in which blood flowing through the blood vessels is treated as a conductor of electrical signals. Vascular walls and other tissues possess electrochemical potentials whose values depend on the state of the tissue (i.e., normal, inflamed, damaged, etc.). Potentials measured with platinum electrodes implanted into the tissue can serve as a source of information about the presence or absence of certain pathological states in the vicinity of the implanted electrode. Based on the above model, Nordenström proposed and realized an electrochemical method of treatment for malignant carcinomas by passing DC current through the affected areas of tissue in order to impose certain potentials upon it $[8,9]$.

Another novel medical treatment also has electrochemical basis, viz., detoxification by means of electrochemically controlled hemosorption [10,11]. In this electrochemical model, the hemosorbent was considered to be a porous electrode immersed in aqueous $0.15 \mathrm{M}$ sodium chloride solution. Based on such an approach, an important conclusion was reached as to the mechanism of interaction between the negatively charged formed elements of blood and the activated carbon hemosorbent. The sign and magnitude of the charge of the hemosorbent surface is determined by its potential. The latter, in turn, depends on the nature of the activated carbon material, since the composition of the electrolyte (blood) remains virtually unchanged.

The electrochemical model of hemosorption has made it possible to find a new approach to identifying new promising materials suitable as potential hemosorbents. This is important, since the requirements towards "good" hemosorbents are quite rigorous and somewhat selfcontradictory: on the one hand, such a material must be indifferent towards blood, while on the other it should maintain high adsorption activity towards the toxicants being removed from blood. By treating the hemosorbent/blood interface as an electrochemical system, authors $[10,11]$ were able to assert the possibility of controlling the removal of toxicants from blood via polarization of the hemosorbent (which is usually a porous carbon material). An important aspect of this, however, is the mechanism of interaction between the carbon material and the electrolyte (blood), since adsorption on activated carbon may include the occurrence of Faradaic processes. Such processes may occur in cases where the potential of the hemosorbent in blood is comparable to the reduction or oxidation potential of the toxicant.

It is well known that Faradaic processes (especially electrooxidation) can lead to highly undesirable effects in blood. For example, anodic oxidation of proteins leads to their denaturation [12]. At the same time, Frumkin showed [13] that the potential of an electrode depends on the adsorption of organic and inorganic substances on it.

Unfortunately, electrochemical data are rarely given or utilized in carbon adsorption research. For instance, authors of [14] considered the properties of the carbon/electrolyte interface when certain cations are adsorbed; however, while the authors [14] recounted Frumkin's conception of 
activated carbon as an oxygen electrode, they considered chromene-like groups that generate resonance-stabilized carbonium ions to be the initiators of adsorption activity of carbons [15].

Thus, consideration of carbon potential may help elucidate the mechanism of adsorption on carbons and reveal the presence or absence of Faradaic processes during it. For this purpose the mathematical expressions given in [16] can be used, which are based on Frumkin's conception of activated carbon as a perfectly polarizable electrode, i.e. an electrode whose state is fully dependent on the amount of electrical charge consumed [13]. The total charge $q$ of a perfectly polarizable electrode is a function of both electrode potential $E$ and the amount $\Gamma$ of adsorbed electrochemically indifferent surface-active substance. Since the measurements are being made in an open circuit, an assumption can be made that the total charge of the carbon $q$ is constant

$$
q=q(E, \Gamma)=\text { const }
$$

and therefore its total differential is equal to zero:

$$
\mathrm{d} q=\left(\frac{\partial q}{\partial E}\right)_{\Gamma} \mathrm{d} E+\left(\frac{\partial q}{\partial \Gamma}\right)_{E} \mathrm{~d} \Gamma=0
$$

In line with [16,17], $(\partial q / \partial E)_{\Gamma}=C_{\infty}$, i.e. the capacitance of the electrode at a sufficiently high frequency; and $-(\partial q / \partial \Gamma)_{E}=n F$. Therefore:

$$
C_{\infty} \mathrm{d} E-n F \mathrm{~d} \Gamma=0
$$

which can be rearranged as

$$
C_{\infty} \mathrm{d} E=n F \mathrm{~d} \Gamma
$$

Isolating $\mathrm{n}$, one would obtain:

$$
n=\frac{C_{\infty}}{F} \frac{\mathrm{d} E}{\mathrm{~d} \Gamma}
$$

Finally, if the assumption is made that the ratio $d E / d \Gamma \approx \Delta E / \Delta \Gamma$, i.e., replacing the first derivative of potential with respect to adsorption by the finite ratio of changes in $E$ and $\Gamma$, the following expression is obtained, from which the effective number of electrons can be estimated:

$$
n=\left(C_{\infty} \cdot \Delta E\right) /(F \cdot \Delta \Gamma),
$$

where $n$ - effective number of electrons needed for the elementary act of adsorption and/or Faradaic process, $C_{\infty}(F)$ - differential capacitance of the adsorbent, $\triangle E / V$ - OCP shift corresponding to a relatively short period of time $t, F\left(=96500 \mathrm{C} \mathrm{mol}^{-1}\right)$ - Faraday's constant, $\Delta \Gamma / \mathrm{mol}$ - change in the adsorption (Gibbs' surface excess) of the adsorbate during time $t$. Equation (3) can be used for computations of the effective number of electrons. Thus, the empirical data needed to calculate the value of $n$ are the open-circuit potentials of activated carbon and corresponding values of adsorption. The value of differential capacitance $C_{\infty}=100 \mathrm{~F}$ was used for $1 \mathrm{~g}$ of activated carbon according to the data in [18]. An approximation was made that the capacitance $C_{\infty}$ of the adsorbent is weakly dependent on the electrode potential and Gibbs' adsorption of the adsorbate.

With the above considerations, the effective number of electrons transferred in the elementary act of adsorption process or Faradaic process was chosen as the criterion of suitability of carbon materials for use as hemosorbents: viz., the virtual absence of Faradaic processes points to the suitability of such hemosorbents. The adsorption of certain undissociated organic toxicants and 
cupric ions was chosen for a model-based investigation of the applicability of the concept of effective charge transfer for hemosorption.

\section{Experimental}

An IPC-Pro L potentiostat (Volta Co. Ltd, Russia) was used for measurements of polarization curves; it was also utilized for OCP measurements. A saturated silver/silver chloride electrode was used as the reference electrode in all measurements. Adsorption of acetone and 2-methyl-2propanol (tert-butanol, TB) was investigated using gas chromatography. An SRI 310C chromatograph (SRI Instruments, USA) with a $1 \mathrm{~m}$ HayeSep-D packed column and a catalytic combustion detector, as well as a Shimadzu GC17 chromatograph with a CarboWAX 20M phase, were used. $0.150 \mathrm{M} \mathrm{NaCl}$ or $0.200 \mathrm{M} \mathrm{Na}_{2} \mathrm{SO}_{4}$ solutions were used as a supporting electrolyte in adsorption and potential measurements of the organic compounds and in measurements of the initial carbon potentials.

Adsorption of organic compounds and cupric ions was investigated on AG-3 activated carbon; the OCP value of the initial sample measured in $0.200 \mathrm{M} \mathrm{Na}_{2} \mathrm{SO}_{4}$ was $50 \mathrm{mV}$ (vs. $\mathrm{Ag} / \mathrm{AgCl}$ ). Modification of the AG-3 carbon was carried out according to $[10,11]$ in the cell shown in Fig. 1. The granules of initial activated carbon were placed in the anode (1) and cathode (2) chambers separated by perforated discs made from a dielectric material (8), with the granules subsequently compressed by the current-carrying discs (6) by turning the bolts (7). A peristaltic pump was used to pass an aqueous sodium chloride solution through the assembled cell at a flow rate of $50 \mathrm{~mL} / \mathrm{min}$. Carbon was modified galvanostatically with a current of $0.75 \mathrm{~A}$ for 10 to 90 min, with subsequent washing of the cathodically and anodically modified carbons to a $\mathrm{pH}=7$. As a result of the modification, carbons with OCP values in the range between $+475 \mathrm{mV}$ and $-775 \mathrm{mV}$ ( $v s$. $\mathrm{Ag} / \mathrm{AgCl}$ ) were obtained and used for further experiments.

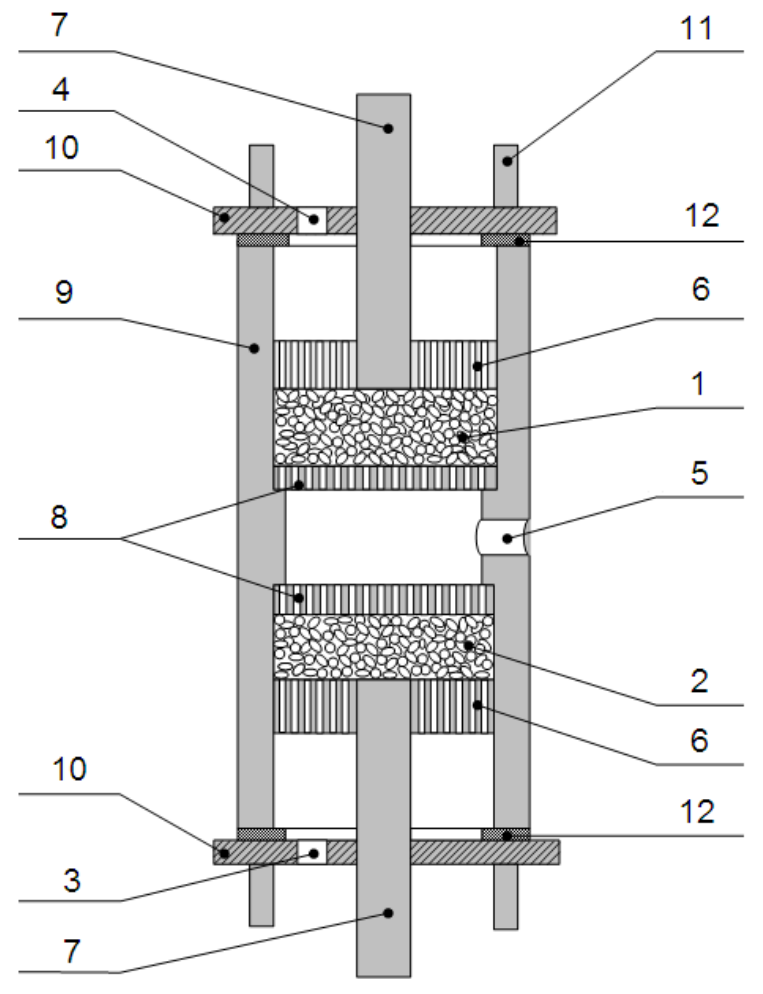

Figure 1. Flow-through cell for the electrochemical modification of activated carbon: 1 - anodic chamber, 2 - cathodic chamber, 3 -electrolyte inlet, 4 - electrolyte outlet, 5 -alternative inlet for solution or reference electrode, 6 -stainless steel perforated current-carrying disc, 7-stainless steel bolt, 8-perforated polymer disc, 9-housing, 10 - covers, 11 - screw, 12 - rubber gasket. 
The amount of copper adsorbed on activated carbon was determined spectrometrically by measuring the concentration change of $\mathrm{Cu}^{2+}$ ions in aqueous $0.100 \mathrm{M} \mathrm{CuSO}_{4}$ solution on scanning UV/visible spectrophotometers Genesys 10uv (Thermo Scientific, USA) at $\lambda_{\max }=808 \mathrm{~nm}$ in the form of copper sulfate and Beckman-Coulter DU 800 at $\lambda_{\max }=607 \mathrm{~nm}$ in the form of an amino complex. Carbon OCP was recorded simultaneously with solution sampling. Contact time of the activated carbon with the solution was $30 \mathrm{~min}$.

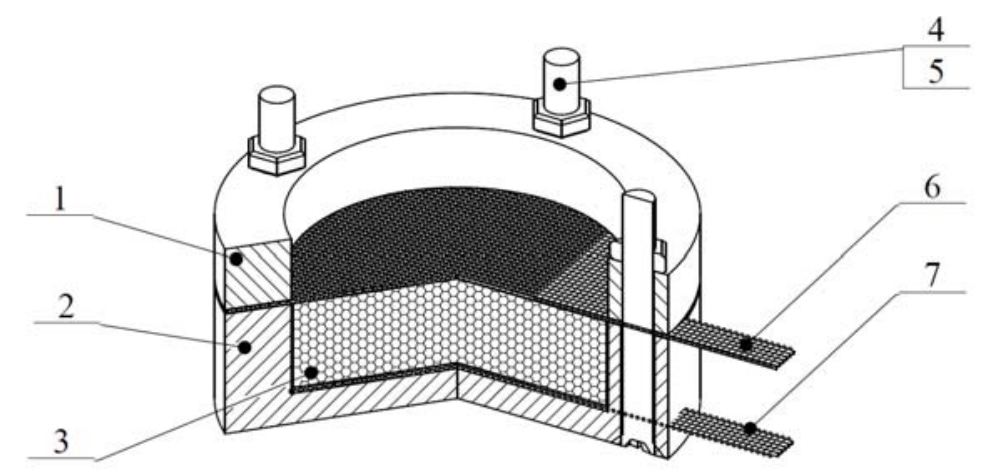

Figure 2. Non-flow-through cell for measurement of granulated carbon OCP: 1 - clamp cover, 2 - housing, 3-cylindrical chamber, 4,5-Teflon bolts and nuts, 6,7-current-carrying stainless steel meshes.

Carbon OCP was measured in a non-flow-through apparatus described in [19], shown in Fig. 2. This apparatus was immersed in solution with constant stirring at $100 \mathrm{rpm}$ using a magnetic stirrer. Carbon granules were placed in the cylindrical chamber (3) of the apparatus and compressed against the stainless steel meshes $(6,7)$ by the cover $(1)$. The current-carrying meshes and the reference electrode were connected to the potentiostat, and the time dependence of OCP values was recorded. Since the surface area of the carbon is $1000 \mathrm{~m}^{2} / \mathrm{g}$, while the surface area of the steel mesh is on the order of $10^{-4}-10^{-5} \mathrm{~m}^{2}$, the potential measured is that of the carbon and not of the current-carrying steel.

Cyclic voltammetry was used to obtain a potentiodynamic charging curve for computation of differential capacitance of AG-3 activated carbon. A single granule of AG-3 carbon was placed in a three-electrode cell. Thermally expanded graphite was used as the current collector and the auxiliary electrode. The cyclic voltammogram was collected at a scan rate of $0.5 \mathrm{mV} / \mathrm{s}$ in the range between $-800 \mathrm{mV}$ and $+600 \mathrm{mV}$.

\section{Results and Discussion}

As noted above, carbon modification in the present work was performed according to the method previously developed in $[10,11]$. It was shown in [11] that anodic and cathodic treatment of carbon led to significant changes in the composition of its surface functional groups (Table 1).

As seen from the data shown in Table 1, cathodic treatment of activated carbon drastically reduced the amount of acidic functional groups on carbon surface, while anodic treatment increases their amount. This trend is observed regardless of the acidity of the electrolyte used for modification. Thus, cathodic treatment results in the reduction of oxygenated surface functional groups, while anodic treatment leads to the oxidation of carbon atoms.

OCP data for unmodified and electrochemically modified AG-3 carbon samples during contact with solutions of acetone (in $0.150 \mathrm{M} \mathrm{NaCl}$ ) and TB (in $0.20 \mathrm{M} \mathrm{Na}_{2} \mathrm{SO}_{4}$ ) were obtained as a time dependence, with corresponding concentration changes of the organic compounds in solution. A typical graph of OCP and adsorption, calculated from chromatographic data, is shown in Fig. 3 (for TB on unmodified AG-3); similar dependences were obtained for all other samples. Zero 
adsorption corresponds to the initial potential of AG-3 in the experiment in the investigated solution.

Table 1. Influence of electrochemical modification of activated carbon on its surface functional groups [11].

\begin{tabular}{|r|c|c|c|}
\hline \multirow{2}{*}{ Type of treatment } & \multicolumn{3}{|c|}{ Amount of functional group, $\mathrm{mmol} \mathrm{g}^{-1}$} \\
\cline { 2 - 4 } & Carboxyl & Lactone & Phenol \\
\hline Initial untreated carbon & 0.47 & 0.10 & 0.18 \\
\hline $\mathrm{NaCl}$ solution $(\mathrm{pH}=11.5)$ & & & 0 \\
cathodic & 0 & 0 & 0.32 \\
anodic & 0.41 & 0.30 & \\
\hline $\mathrm{NaCl}$ solution $(\mathrm{pH}=1.4)$ & & 0.04 & 0.20 \\
cathodic & 0.15 & 0.16 & 0.20 \\
anodic & 0.51 & & \\
\hline
\end{tabular}

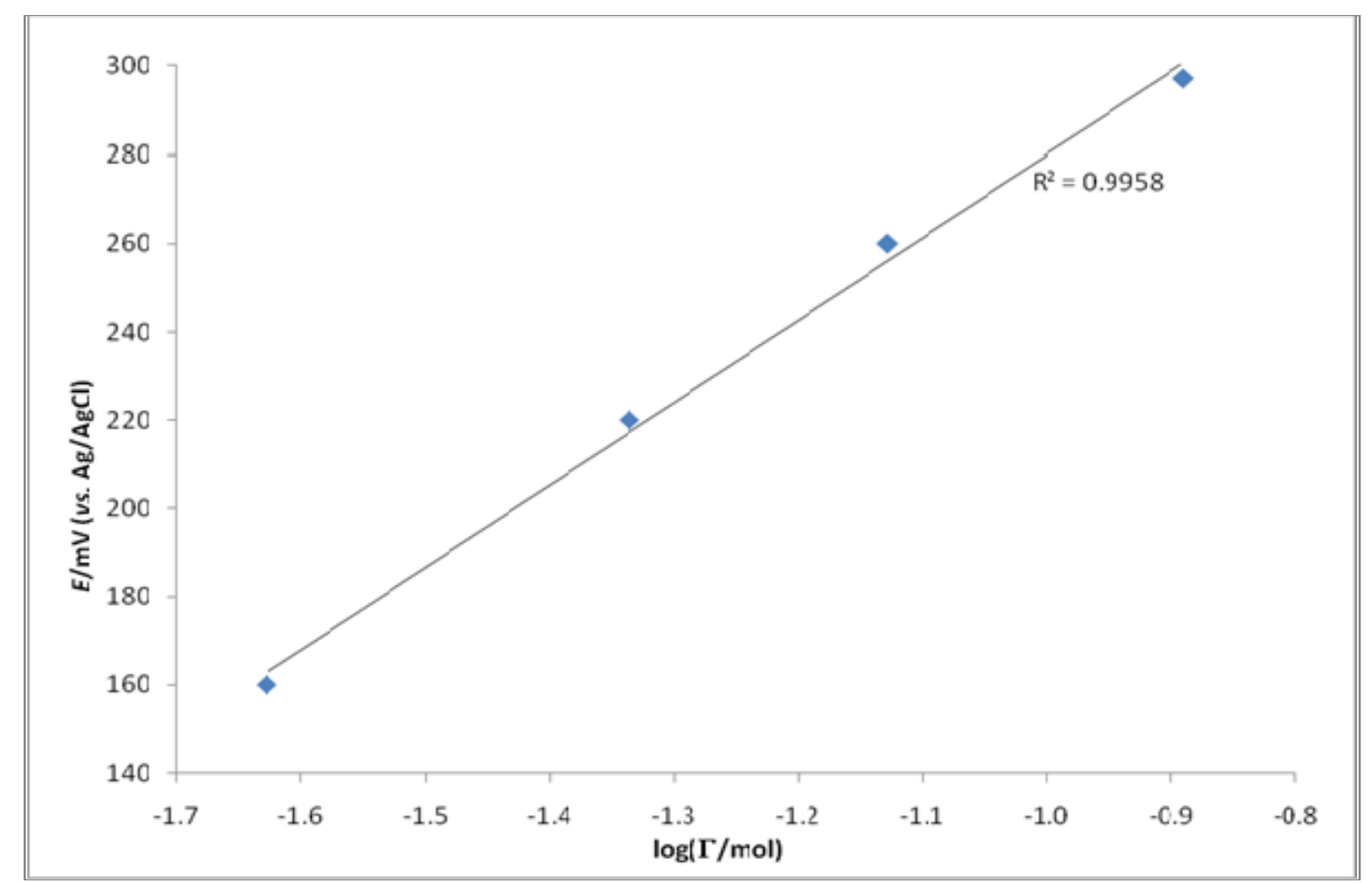

Figure 3. Dependence of the OCP of $A G-3$ carbon on TB adsorption from $0.20 \mathrm{M} \mathrm{Na}_{2} \mathrm{SO}_{4}$. Initial TB concentration: $77 \mathrm{~g} / \mathrm{L}$.

\section{Differential Capacitance}

The differential capacitance of the AG-3 activated carbon was computed based on the potentiodynamic data. An $8.0 \mathrm{mg}$ carbon sample was used, and potentials were scanned in the range between $-700 \mathrm{mV}$ and $+500 \mathrm{mV}$ at a scan rate of $0.5 \mathrm{mV} / \mathrm{s}$. The resulting dependence of potential on differential capacitance is shown in Fig. 4.

A minimum at $C_{\min }=78.7 \mathrm{~F}$ per gram and a maximum at $C_{\max }=121 \mathrm{~F}$ per gram were observed. The average value of differential capacitance from the calculated results was $C_{\text {avg }}=95.4 \mathrm{~F}$ per gram of carbon, which closely matches the literature data [18]. Thus, the value of capacitance $C_{\infty}=100 \mathrm{~F}$ per gram of carbon was used in all further computations. 


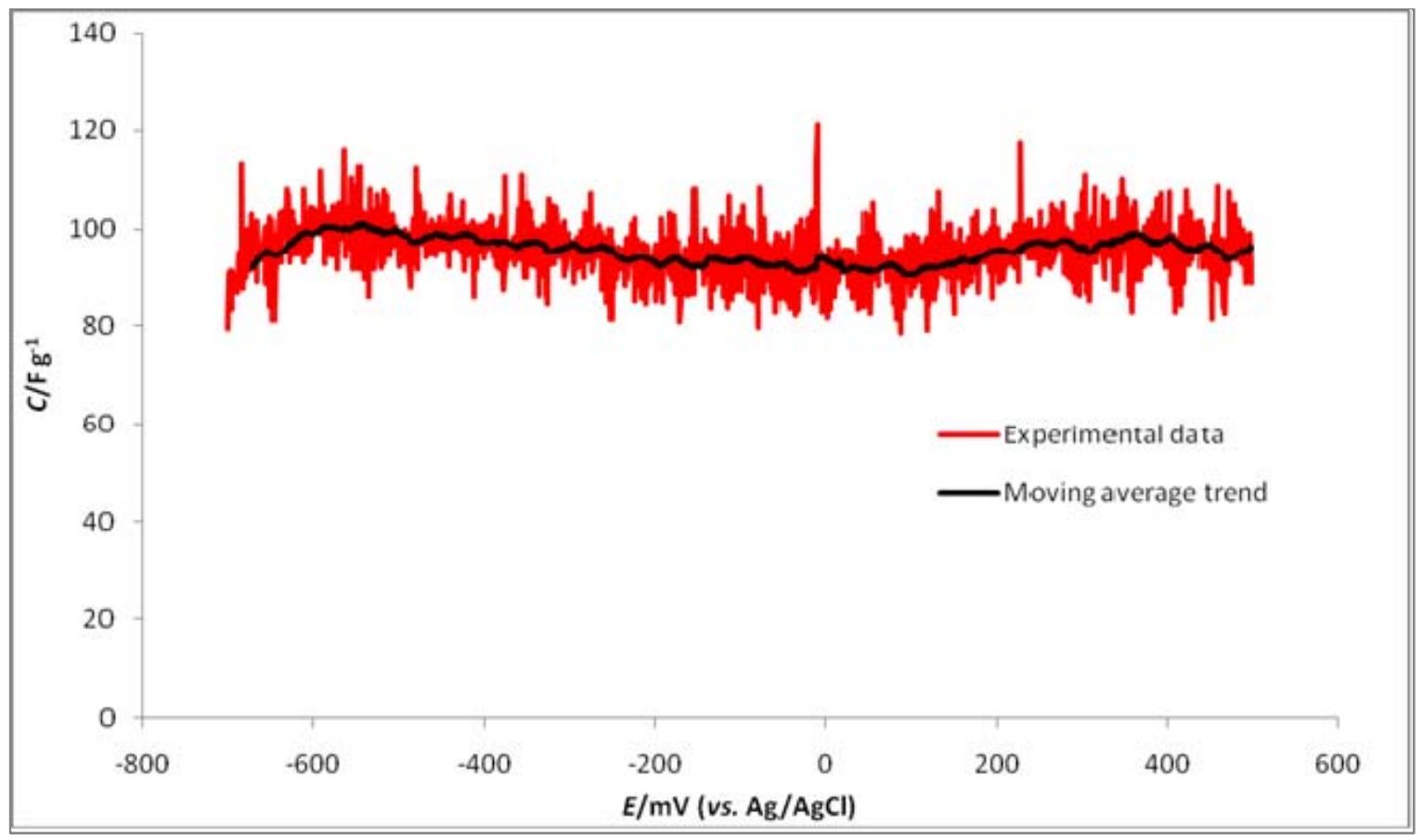

Figure 4. Differential capacitance per gram of AG-3 activated carbon as a function of potential.

\section{Adsorption of Organic Molecules}

Based on the final OCP and adsorption values for unmodified and electrochemically modified AG-3 carbon samples, effective numbers of electrons were calculated for acetone and TB adsorption. The results are summarized in Tables 2-3. It should be noted that these calculations reflect the integral character of effective charge transfer in the range from $E_{\text {initial }}$ to $E_{\text {final }}$.

Table 2. Adsorption of tert-butanol on AG-3 carbon. Potentials reported vs. Ag/AgCl.

\begin{tabular}{|c|c|c|c|c|c|}
\hline$m_{\text {carbon }} / \mathrm{g}$ & $E_{\text {initial }} / \mathrm{mV}$ & $E_{\text {final }} / \mathrm{mV}$ & $\Delta E / \mathrm{mV}$ & $\Delta \Gamma / \mathrm{mmol}$ & $n$ \\
\hline 2.0157 & -670 & -590 & +80 & 12 & 0.014 \\
\hline 1.8550 & -267 & -8 & +259 & 12 & 0.043 \\
\hline 2.0461 & 0 & +165 & +165 & 11 & 0.046 \\
\hline 1.9979 & +35 & +280 & +245 & 9.7 & 0.046 \\
\hline 1.9763 & +85 & +300 & +215 & 9.9 & 0.035 \\
\hline 2.1517 & +280 & +450 & +170 & 13 & 0.034 \\
\hline 1.6763 & +380 & +575 & +195 & 11 & 0.018 \\
\hline 1.6747 & +425 & +540 & +115 & 10. & 0.014 \\
\hline
\end{tabular}

Table 3. Adsorption of acetone on AG-3 carbon. Carbon mass $\mathrm{m}=10.00 \mathrm{~g}$. (Potentials vs. Ag/AgCl).

\begin{tabular}{|c|c|c|c|c|}
\hline$E_{\text {initial }} / \mathrm{mV}$ & $E_{\text {final }} / \mathrm{mV}$ & $\Delta E / \mathrm{mV}$ & $\Delta \Gamma / \mathrm{mmol}$ & $n$ \\
\hline+440 & +580 & +140 & 72 & 0.020 \\
\hline+310 & +460 & +150 & 88 & 0.018 \\
\hline+190 & +290 & +100 & 95 & 0.011 \\
\hline+102 & +190 & +88 & 110 & 0.0084 \\
\hline-96 & +45 & +141 & 110 & 0.013 \\
\hline-144 & -10 & +134 & 98 & 0.014 \\
\hline
\end{tabular}


Calculated values for the effective number of electrons in the course of adsorption of organic molecules on AG-3 carbon were quite small (0.0084 to 0.046). This may indicate that Faradaic processes do not contribute significantly to the adsorption process of these substances. Importantly, adsorption of all of these compounds on AG-3 carbon is accompanied by a positive shift in carbon OCP, which points to an electrochemical mechanism of adsorption (since changes in an electrochemical parameter are observed).

\section{Adsorption of Cupric lons}

Similar adsorption experiments were performed on AG-3 carbon samples in aqueous $\mathrm{CuSO}_{4}$. The most important results of these experiments are summarized in Table 4. A typical time dependence of the OCP and concentration (for unmodified AG-3) is shown in Fig. 5. Fig. 6 shows the dependence of the "local" effective number of electrons (calculated between data points) on potential in the course of the experiment described in Fig. 6. Discrete values of $(E, n)$ correspond to the elapsed time, as shown next to each point in the figure. It can be seen from Fig. 6 that the process of adsorption reaches equilibrium after about $30 \mathrm{~min}$, as the "local" effective number of electrons transferred reaches zero (within the precision of the experimental data).

Table 4. Integral values of the effective numbers of electrons $\mathrm{n}$ in the course of $\mathrm{Cu}^{2+}$ ion adsorption on $\mathrm{AG}-3$ carbon with various initial potentials. Carbon masses ( $m_{\text {carbon }}$ ) as shown below. (Potentials vs. Ag/AgCl)

\begin{tabular}{cccccc}
\hline$m_{\text {carbon }} / \mathrm{g}$ & $E_{\text {init }} / \mathrm{mV}$ & $E_{\text {final }} / \mathrm{mV}$ & $\Delta E / \mathrm{mV}$ & $\Gamma / \mathrm{mmol}$ & $n$ \\
\hline 5.022 & -775 & 40 & 815 & 2.1 & 2.07 \\
4.990 & -700 & 40 & 740 & 1.8 & 2.13 \\
5.007 & -580 & 40 & 620 & 1.5 & 2.15 \\
5.001 & -470 & 47 & 517 & 1.4 & 1.91 \\
\hline
\end{tabular}

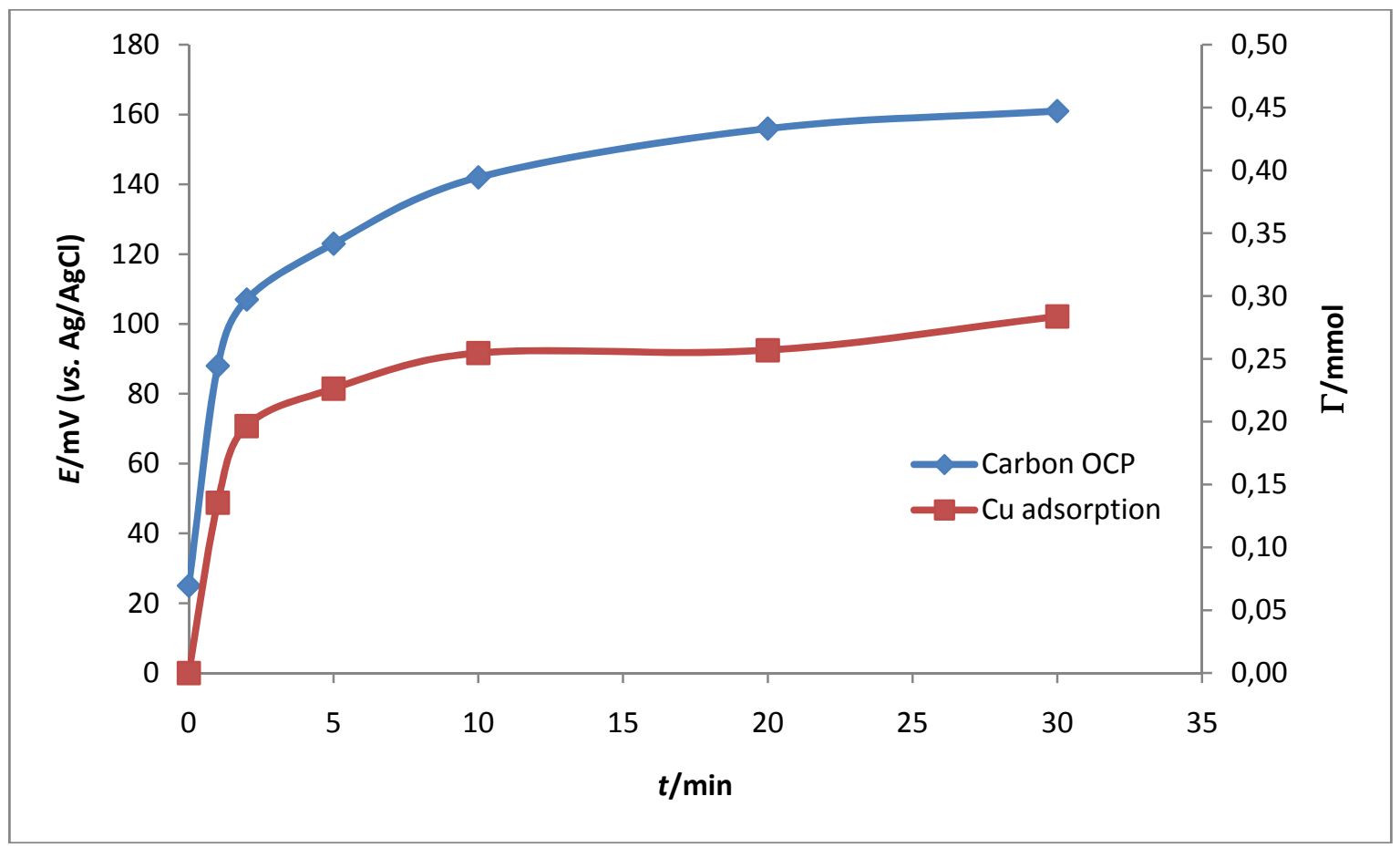

Figure 5. Time dependence of the OCP of unmodified AG-3 carbon and the adsorption of cupric ions from solution. 


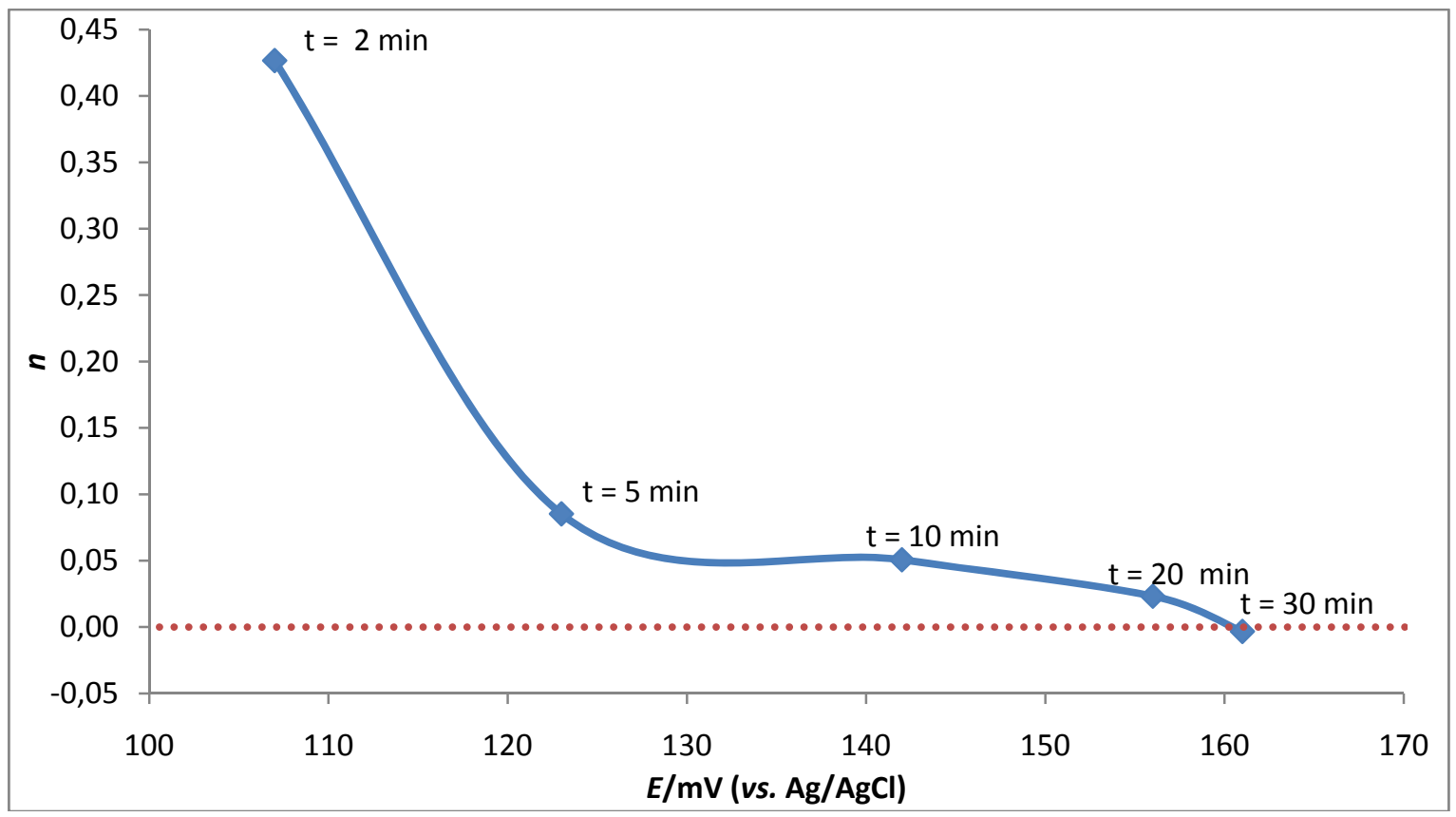

Figure 6. Dependence of the effective number of electrons on the OCP of unmodified AG-3 carbon during $\mathrm{Cu}^{2+}$ adsorption.

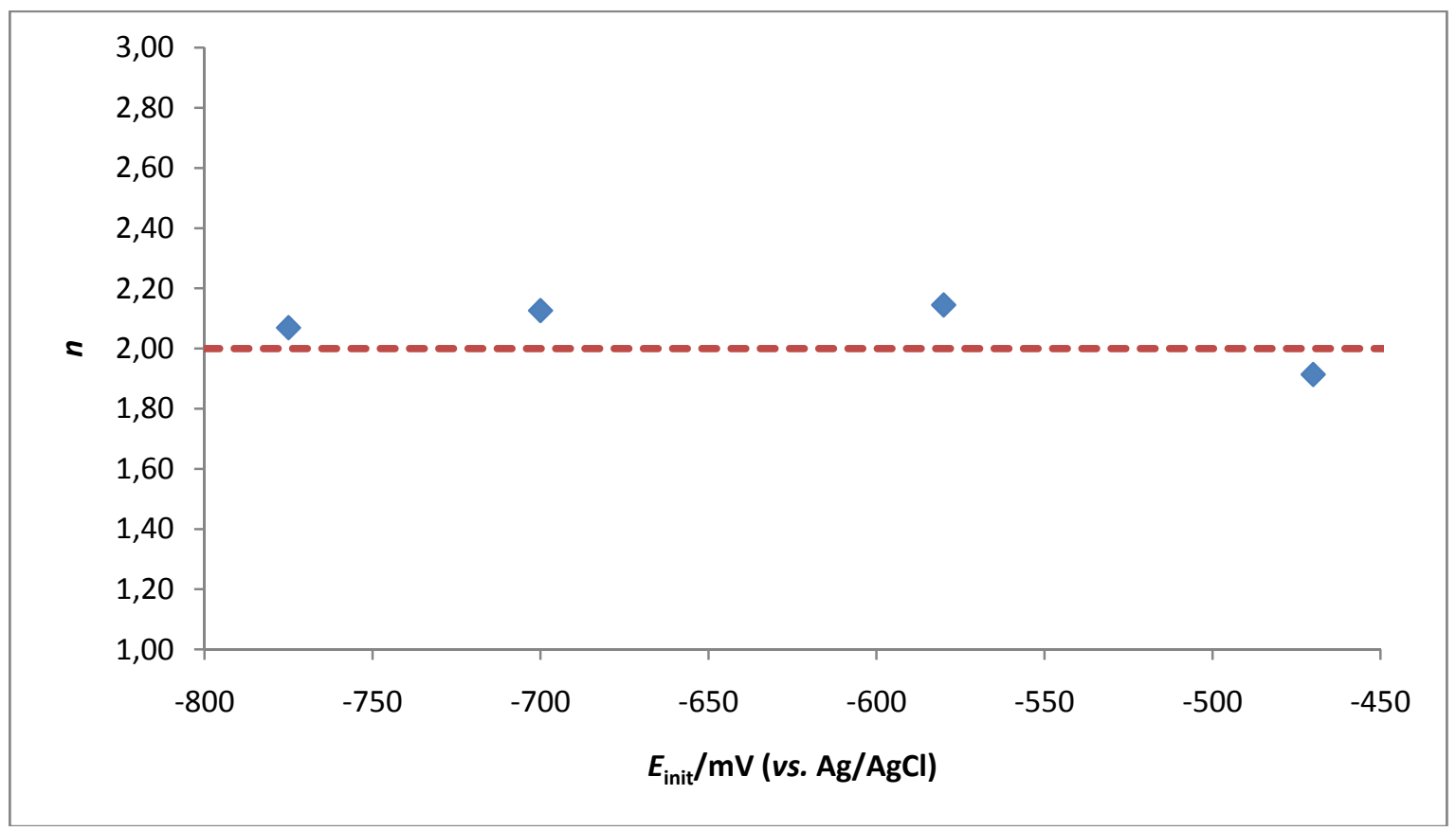

Figure 7. Dependence of the integral effective number of electrons on the initial open-circuit potential of carbon for $\mathrm{Cu}^{2+}$ cation adsorption on $\mathrm{AG}-3$ carbon.

For initial carbon potentials in the range between -775 and $-470 \mathrm{mV}(\mathrm{vs}$. $\mathrm{Ag} / \mathrm{AgCl})$, the data obtained (Table 4 and Fig. 7) shows effective numbers of electrons $n \approx 2$. This corresponds to the two-electron Faradaic open-circuit process of copper electroreduction on the carbon:

$$
\mathrm{R}^{\prime}-\mathrm{C}+\mathrm{Cu}^{2+}+\mathrm{H}_{2} \mathrm{O} \rightarrow \mathrm{R}^{\prime}-\mathrm{C}=\mathrm{O}+\mathrm{Cu}^{0}+2 \mathrm{H}^{+}
$$

This is also corroborated by the appearance of a characteristic reddish-colored copper deposit on the carbon granules after cathodically modified AG-3 is immersed in aqueous $\mathrm{CuSO}_{4}$. Thus, it is possible to detect the presence of Faradaic processes in the course of adsorption by measuring OCP and calculating the effective number of electrons. (It should also be noted that, while noble 
metals are known to deposit onto carbons [20], the literature does not relate this to the OCP of carbon.)

\section{Probability of One-Electron Copper Reduction}

Importantly, one should consider the probability of the one-electron reduction process in the course of adsorption (as a competing process, with possible further transformation of $\mathrm{Cu}^{+}$):

$$
\begin{aligned}
& \mathrm{Cu}^{2+}+\mathrm{e}^{-} \rightarrow \mathrm{Cu}^{+} \\
& \mathrm{Cu}^{+}+\mathrm{e}^{-} \rightarrow \mathrm{Cu}^{0}
\end{aligned}
$$

The determination of $\mathrm{Cu}^{+}$in solution is rather difficult, since it quickly disproportionates in solution:

$$
2 \mathrm{Cu}^{+} \rightarrow \mathrm{Cu}^{2+}+\mathrm{Cu}^{0}
$$

In electrolytic refining of copper [21], bulk $\left[\mathrm{Cu}^{+}\right]$concentration for aqueous $\mathrm{CuSO}_{4}$ in equilibrium with metallic copper was $c a$. three orders of magnitude below $\left[\mathrm{Cu}^{2+}\right]$, i.e. virtually negligible. Other investigations [22-26], however, suggest a stepwise mechanism for the deposition of cupric ions/ionization of metallic copper, with excess $\mathrm{Cu}^{+}$in the interphase region as an intermediate between $\mathrm{Cu}^{0}$ and $\mathrm{Cu}^{2+}$.

While a polarographic method of $\mathrm{Cu}^{+}$determination in solution has been proposed [27], it involves the addition of organic ligands that might interact with activated carbon, making this method impractical for the present work. In addition, if $\mathrm{Cu}^{+}$only exists in excess near the interface, as suggested by [22-26], it would be difficult to detect it at an additional electrode removed from the vicinity of the carbon surface. Thus, it is not possible to elucidate the involvement of $\mathrm{Cu}^{+}$in the investigated processes. However, regardless of mechanistic details, Faradaic reduction of $\mathrm{Cu}^{2+}$ to metallic $\mathrm{Cu}^{0}$ undoubtedly occurs in the above experiments; this is also corroborated by the calculated values of $n$.

\section{Conclusions}

Thus, experimental data on the effective number of electrons unequivocally confirm an electrochemical mechanism of hemosorption. All effective numbers of electrons were calculated assuming that the electric double layer capacitance remained constant despite significant potential changes of the carbon. For the model processes of acetone and TB adsorption it was shown that the adsorption of an organic toxicant on AG-3 activated carbon took place virtually without any electron transfer, i.e. Faradaic processes did not occur, while the carbon potential did change in the course of adsorption. The interaction of copper cations with the surface of activated carbon depended on carbon potential: for potentials more negative than $-470 \mathrm{mV}(\mathrm{vs}$. $\mathrm{Ag} / \mathrm{AgCl})$, the two-electron Faradaic process of copper deposition $\mathrm{Cu}^{2+}+2 \mathrm{e}^{-} \rightarrow \mathrm{Cu}^{0}$ occurred, as reflected by calculated values of the effective number of electrons.

Therefore, it is possible to determine the mechanism of adsorbate interaction with an activated carbon hemosorbent by performing open-circuit potential and adsorption measurements. The effective number of electrons can be calculated and utilized as a criterion of hemosorbent suitability, since it allows the detection of Faradaic processes between the hemosorbent and adsorbate. It is important that the phenomenon of partial transfer of charge allows working hemosorbens to be reclassified according to their electric effectiveness.

Acknowledgements: This study is supported by funds from the Center for Research and Scholarship Fund of Liberty University. Grant \# 021_030110. We wish to thank the anonymous referee for a thorough reading of and valuable suggestions for the present paper. 


\section{References}

[1] P.N. Sawyer, J.W. Pate, Am. J. Physiol. 175 (1953) 113-117

[2] P.N. Sawyer, J.W. Pate, C.S. Weldon, Am. J. Physiol. 175 (1953) 108-112

[3] G. Guglielmi, F. Viñuela, I. Sepetka, V. Macellari, J. Neurosurg. 75 (1991) 1-7

[4] G. Guglielmi, F. Viñuela, J. Dion, G. Duckwiler, J. Neurosurg. 75 (1991) 8-14

[5] G. Guglielmi, F. Viñuela, in Neurosurgery Clinics of North America: Endovascular Approach to Central Nervous System Disease, L.N. Hopkins, Ed., Saunders, Philadelphia, PA, 1994, vol. 5, p. 427-435

[6] G. Guglielmi, in: Neuroimaging Clinics of North America: Interventional Neuroradiology, F. Viñuela, J. Dion, G. Duckwiler, Eds., Saunders, Philadelphia, PA, 1992, vol.2, p. 269-278.

[7] B.E.W. Nordenström, Biologically closed electrical circuits, Nordic medical publication, Stockholm, 1983, p. 358.

[8] B.E.W. Nordenström, in New radiologic imaging and intervention in general surgery, G. Ussia, F. Bassi, J.T. Feirucci, Eds., Masson, Milano, 1989, p. 143-159

[9] B.E.W. Nordenström, Electromagnetic Biology and Medicine 3 (1984) 137 - 154

[10] Mark M. Goldin, A.G. Volkov, Yu.S. Goldfarb, Mikhail M. Goldin, J. Electrochem. Soc. 153 (2006) J91-J99

[11] M.R. Tarasevich, Mark M. Goldin, Ye.A. Luzhnikov, V.A. Bogdanovskaya, in Itogi Nauki i Tekhniki:Electrochemistry, Yu.M. Polukarov, Ed., VINITI, Moscow, 1990, vol.31, p. 127-150 [in Russian]

[12] asilyev Yu.B., Sergienko V. I., Elektrokhimiya, 23 (1987) 661-662 [in Russian]

[13] A. N. Frumkin, E. A. Ponomarenko, R. H. Burshtein, Doklady Acad. Sci. USSR 149 (1963) 1123-1126

[14] Chemistry and physics of carbon, L.R.Radovich, Ed., vol. 27, Marcel Dekker, NY, 2001

[15] V.A. Garten, D.E. Weiss, Rev. Pure and Applied Chem 7 (1957) 69-122

[16] A.N. Frumkin, V.I. Melik-Gaykazyan, Doklady Acad. Sci. USSR 77 (1951) 855-858

[17] B.M. Grafov, V.V. Elkin, J. Electroanal. Chem. 304 (1991) 31-40

[18] A.Yu. Rychagov, N.A. Urisson and Yu.M. Volfkovich, Russ. J. Electrochem. 37 (2001) 11721179

[19] Mikhail M. Goldin, V.A. Kolesnikov, M.Sh. Khubutiya, A.G. Volkov, G.J. Blanchard, A.K. Evseev, Mark M. Goldin, J. Appl. Electrochem. 38 (2008) 1369-1374

[20] M.P. Yunusov, I.V. Perezdrienko, Sh.N. Namazbaev, T.B. Molodozhenyuk, Khimicheskaya promyshlennost 8 (2003) 382-385 [in Russian]

[21] N.P. Fedotyev, A.F. Alabyshev, A.P. Rotinyan, P.M. Vyacheslavov, P.B. Zhivotinskiy, A.A. Galnbek, Prikladnaya elektrokhimiya, $2^{\text {nd }}$ ed., Khimiya, Leningrad, 1967, $600 \mathrm{p}$ [in Russian]

[22] A.I. Molodov, G.N. Markosyan, I.R. Lyumkis, V.V. Losev, Elektrokhimiya 9 (1973) 1460-1467 [in Russian]

[23] A.I. Molodov, G.N. Markosyan, V.V. Losev, Elektrokhimiya 7 (1972) 263-267 [in Russian]

[24] A.I. Molodov, Elektrokhimiya 6 (1970) 365-369 [in Russian]

[25] V.V. Losev, L.E. Sribnyi, A.I. Molodov, Elektrokhimiya 2 (1966) 1431-1437 [in Russian]

[26] Yu.S. Dmitriev, A.A. Murtazina, A.S. Kolosov, Elektrokhimiya 5 (1969) 106-108 [in Russian]

[27] J.A. Altermatt, S.E. Manahan, Anal. Chem. 40 (1968) 655-657

(C) 2011 by the authors; licensee IAPC, Zagreb, Croatia. This article is an open-access article distributed under the terms and conditions of the Creative Commons Attribution license (http://creativecommons.org/licenses/by/3.0/) (cc) BY 